\title{
Is adiposity associated with objectively measured physical activity and sedentary behaviors in older adults?
}

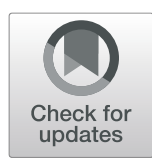

Wenfei Zhu ${ }^{1 *} \mathbb{D}$, Zhiwei Cheng ${ }^{1}$, Virginia J. Howard ${ }^{2}$, Suzanne E. Judd ${ }^{3}$, Steven N. Blair ${ }^{4}$, Yuliang Sun ${ }^{1}$ and Steven P. Hooker ${ }^{5}$

\begin{abstract}
Background: Many older adults in the U.S. do not achieve the recommended amount of physical activity (PA) to fully realize a myriad of health benefits. Adiposity is one of those important correlates of PA and sedentary behaviors. However, the full extent to which adiposity is associated with PA and stationary time (STA) is uncertain. Therefore, we examined the association of adiposity with objectively measured PA and STA in black and white older adults.
\end{abstract}

Methods: We conducted a cross-sectional study of older adults enrolled in the REasons for Geographic and Racial Differences in Stroke (REGARDS) Study 2003-2007 who participated in an ancillary accelerometer study 2009-2013. Assessment of body mass index (BMI) and waist circumference (WC) was completed during an in-home visit in the parent study. PA was measured by Actical ${ }^{T M}$ accelerometers, which provided estimates of moderate-to-vigorousintensity PA (MVPA), light-intensity PA (LPA), and STA for 4-7 consecutive days. Data from accelerometers were standardized to square root percentages of total wear time per day (SqrtMVPA\%, SqrtLPA\%, and SqrtSTA\%). Interactions were tested for BMI and WC by race and sex, separately.

Results: Data were available for 7873 participants (69.8 18.7 yr, 54.2\% women, 31.5\% African American). In mixed linear regression models, significant interactions existed in BMI by race and sex for the SqrtMVPA\%, WC by race and sex for the SqrtMVPA\% and the SqrtLPA\% model $(p<0.05)$. No interaction was significant for the logistic model of meeting the PA guideline or not. In subgroup analyses, BMI was inversely associated with SqrtMVPA\%, SqrtLPA\%, and positively related to SqrtSTA\% in black women, white men and white women after adjustments. Similar patterns were observed between WC and SqrtMVPA\%, SqrtLPA\%, and SqrtSTA\% in all groups, respectively. However, BMI was not associated with SqrtMVPA\% in black men. Those with higher BMI or WC were less likely to meet the PA guideline in all groups.

Conclusions: Adiposity was inversely associated with higher levels of MVPA/LPA and positively associated with higher levels of STA among black and white older adults. Prevention efforts aimed at promoting weight control may be beneficial to prevent physical inactivity and sedentary lifestyle among older adults.

Keywords: Adiposity, Physical activity, Stationary time, Accelerometer, Older adults

\footnotetext{
* Correspondence: wzhu@snnu.edu.cn

'School of Physical Education, Shaanxi Normal University, No. 620, West

Chang'an Avenue, Chang'an District, Xi'an 710119, Shaanxi, China

Full list of author information is available at the end of the article
}

(c) The Author(s). 2020 Open Access This article is licensed under a Creative Commons Attribution 4.0 International License, which permits use, sharing, adaptation, distribution and reproduction in any medium or format, as long as you give appropriate credit to the original author(s) and the source, provide a link to the Creative Commons licence, and indicate if changes were made. The images or other third party material in this article are included in the article's Creative Commons licence, unless indicated otherwise in a credit line to the material. If material is not included in the article's Creative Commons licence and your intended use is not permitted by statutory regulation or exceeds the permitted use, you will need to obtain permission directly from the copyright holder. To view a copy of this licence, visit http://creativecommons.org/licenses/by/4.0/ The Creative Commons Public Domain Dedication waiver (http://creativecommons.org/publicdomain/zero/1.0/) applies to the data made available in this article, unless otherwise stated in a credit line to the data. 


\section{Background}

Epidemiological studies [1-4] have shown that physical activity (PA) is associated with improved physical function, lower prevalence of several chronic diseases, and reduced all-cause premature mortality. The Physical Activity Guidelines for Americans (second edition) [5] recommends adults should do at least $150 \mathrm{~min}$ to 300 min a week of moderate-intensity, or $75 \mathrm{~min}$ to $150 \mathrm{~min}$ a week of vigorous-intensity aerobic activity, or an equivalent combination. The guidelines also emphasize the importance of avoiding prolonged sitting, and provide some new information and guidance on the benefits and practices of moving more and sitting less.

A large proportion of individuals, especially older adults, have very limited PA combined with prolonged stationary time (STA), and thus fail to gain the subsequent health benefits. For example, analyses from the 2003-2004 National Health and Nutritional Examination Survey (NHANES) indicated that the proportion of adherence to the first edition PA guidelines (30 or more minutes of MVPA on 5 of 7 days, accumulated in modified 10 -min bouts) was only $2.4 \% \pm 0.4$ among U.S. older adults aged $\geq 60$ yrs. [6]. A later study [7] using data from NHANES 2005-2006 reported that the proportion of older adults aged 60-69 meeting the recommended level of PA (150 min of MVPA in total per week, accumulated in modified 10 -min bouts) was $8.5 \% \pm 1.5$ for accelerometer measures, while the proportion was $6.3 \% \pm 1.5$ for those aged $\geq 70$ yrs. Analyses from the REGARDS cohort [8] using acceleometry revealed only $6-22 \%$ of the older adults aged $\geq 45 \mathrm{yrs}$. accumulated at least $150 \mathrm{~min}$ of MVPA per week (accumulated in 1-min bouts to reflect the importance of accumulation in older adults). Women and African Americans were more likely to fail to meet the PA guidelines [6, 7]. Other analyses found a significant portion of deaths [2] and higher percentage of health care expenditures [1] were associated with inadequate PA. Thus, more efforts are needed to support and implement programs, practices, and policies to increase PA.

An increasing body of literature has focused on why some individuals do not engage in sufficient PA. Some studies [9-13] have identified demographic, biological, psychological, social, and environmental variables linked to PA levels. However, most studies were based on selfreported PA, which may provide imprecise estimates and impede the understanding of how to promote PA, especially for the highly sedentary population. Objective assessment of PA using accelerometers can overcome many challenges of measuring PA and offers the potential to explain the variances of PA and STA.

Adiposity may be a significant factor related to PA/ STA levels. Cross-sectional and longitudinal studies [14-21] have shown less moderate-to-vigorous-intensity
PA (MVPA) and light-intensity PA (LPA) and more STA are associated with higher level of adiposity, usually measured by body mass index (BMI) or waist circumference (WC). Using the method of Dual Energy X-ray Absorptiometry, research [22] also showed PA is inversely associated with body fat and positively associate with fat-free mass. Furthermore, some recent studies suggest the association between PA and adiposity may be bidirectional, and obesity/overweight may actually predict or precede a lower level of PA and more STA. For example, higher BMI was consistently associated with less objectively measured MVPA and more STA in American and Norwegian adults $[13,23]$. In a study of children, percent body fat measured by dual energy X-ray absorptiometry was negatively associated with subsequent MVPA level [24]. One study in older population [25] illustrated that obesity was associated with lower levels of physical activity and physical function. However, the extent to how adiposity is associated with objectively measured PA and STA, and the adherence to the PA guidelines in older adults remains uncertain. Moreover, in a national cohort of blacks and white adults aged 45 and older, our research team observed significant differences among race/sex groups for mean STA, LPA, MVPA, and proportion achieving $>150 \mathrm{~min} / \mathrm{wk}$. of MVPA [8]. White men had significantly lower STA and higher LPA, MVPA, and proportion achieving $>150$ min/wk. of MVPA than other groups. Nevertheless, whether race or sex moderates the relationship between adiposity and PA remains uncertain.

Thus, we investigated the relationships between indicators of adiposity and objectively measured PA and STA, as well as the adherence to the PA guidelines in a large diverse population of black and white older adults. We hypothesized that adiposity would be associated with PA and STA levels, and obesity/overweight would be a contributor to physical inactivity and failure to meet the PA guidelines in older adults.

\section{Methods \\ Study design and sample}

Participants in this analyses were enrolled from the REasons for Geographic and Racial Differences in Stroke (REGARDS) Study, a national, population-based study to investigate causes of regional and racial disparities in stroke mortality [26]. From 25 January 2003 to 31 October 2007, black and white adults, aged 45 and older, were recruited by random selection of telephone numbers from a commercially available nationwide list (Genesys, Daly City, CA). Trained interviewers obtained demographic information and medical history through a computer-assisted telephone interview. An in-home brief physical examination was conducted after written informed consent was obtained. Examination included 
anthropometric measurements, blood pressure, inventory of prescription and nonprescription medications taken within the previous 2 weeks, phlebotomy, and urine collection. All participants gave informed consent, and the study was approved by the institutional review boards of all participating institutions.

\section{Measures}

Age, race, sex, region of current residence (southeastern U.S. Stroke Belt vs. rest of the U.S.), highest education level, smoking (current, never, past), hypertension (systolic blood pressure $\geq 140 \mathrm{mmHg}$ or diastolic blood pressure $\geq 90 \mathrm{mmHg}$ or self-reported use of antihypertensive medications), and diabetes (fasting glucose $>126 \mathrm{~mL} / \mathrm{dL}$ or nonfasting glucose $>200 \mathrm{~mL} / \mathrm{dL}$ or self-reported use of oral hypoglycemic medications or insulin) were defined from baseline interview and in-home assessment.

During the in-home visit, using an 8-ft metal tape, height was measured without shoes; wearing light clothes, weight was measured using a standard 300-lb calibrated scale. BMI was calculated as weight $(\mathrm{kg})$ divided by height squared $\left(\mathrm{m}^{2}\right)$ and categorized as normal: under $25 \mathrm{~kg} / \mathrm{m}^{2}$, overweight: 25 to $30 \mathrm{~kg} / \mathrm{m}^{2}$, obese: over $30 \mathrm{~kg} / \mathrm{m}^{2}$. Using a cloth tape over skin or lightweight clothing, waist circumference (WC) was measured at the midpoint between the lowest rib on the right side and the top of the iliac crest. WC was used as an indicator of health risk because abdominal obesity is the primary exposure variable [27].

An ancillary accelerometer study was approved and started in October 2008 for implementation into the ongoing REGARDS study. Detailed design and methods for the study have been described elsewhere $[8,28]$. Participants were invited to wear an accelerometer for 7 days for assessment of PA. The protocol used an Actical ${ }^{\mathrm{Tm}}$ accelerometer (Mini Mitter Respironics, Inc. Bend, OR) worn over the right hip attached to a neoprene waistband. Participants were instructed to put on the device after waking up each morning and take it off prior to going to bed each evening. In the ancillary accelerometer study, 8096 of 12,146 participants who were invited and agreed to wear the accelerometer provided usable data with the criterion of $\geq 4$ days with $\geq 10 \mathrm{~h} /$ day of wear time [8]. Absolute time spent in sedentary behavior, LPA, MVPA and the proportions of total accelerometer wear time spent in STA (STA\%), LPA (LPA\%), and MVPA (MVPA\%) were determined to standardize accelerometer wear time [8]. The epoch length was set as $60 \mathrm{~s}$ (1 min). Time spent in LPA or MVPA was presented for every minute meeting the data processing criterion in order to reflect the importance of accumulation. Activity count cut-points were applied to differentiate STA (0$49 \mathrm{cpm})$, LPA (50-1064 cpm), and MVPA (> $1065 \mathrm{cpm})$, respectively [29]. Non-wear periods were defined as a string of zero counts per minute (cpm) for $\geq 120$ consecutive minutes. The average time interval between the $\mathrm{BMI} / \mathrm{WC}$ and PA measures was $5.7 \pm 1.5$ years. After excluding those missing BMI, WC, or any other covariates of interest $(n=222), 7873$ remained for final analyses.

\section{Statistical analyses}

Because of the inherent variability in daily accelerometer wear time, MVPA\%, LPA\%, STA\% rather than the absolute time spent in MVPA, LPA and STA were used as the main dependent variables. As MVPA\%, LPA\%, STA\% failed the normality test, we performed square root transformations to ensure normality of distribution and meet the criteria for regression analysis. The square root transformed MVPA\% (Sqrt MVPA\%), LPA\% (Sqrt LPA\%), STA\% (Sqrt STA\%) showed a normal distribution on visual inspection.

Mixed linear regression models were tested for the hypothesized associations with BMI and WC measures as predictors and Sqrt MVPA\%, Sqrt LPA\%, Sqrt STA\% as response variables, with adjustments for age, sex, race, region of residence, education, BMI, hypertension, smoking, diabetes, and time interval between BMI/WC and PA measures, as well as the random effect of intercept and BMI $\times$ time intervals between measures. Logistic regression analysis was used to estimate odds ratios (ORs) of not meeting the PA guideline (150 min a week of moderate-intensity, or $75 \mathrm{~min}$ a week of vigorousintensity PA, or an equivalent combination of moderateand vigorous-intensity PA), and the associated $95 \%$ CIs, with adjustment for covariates mentioned above.

We were interested in whether associations differed by race and sex, so we tested interactions with BMI and WC by race and sex subgroups (black men, black women, white men and white women). All probability values were based on 2-tailed tests; $p<0.05$ indicated statistical significance. Analyses were conducted using SAS version 9.4 (SAS Institute, Cary, NC).

\section{Results}

Characteristics of participants are displayed in Table 1 . Among the 7873 participants, $54.2 \%$ were women, 31.5\% were black, $44.5 \%$ were college graduates or above, and $54.5 \%$ were from the stroke-belt region of the United States. At baseline of the parent study, 27.7\% did not report performing any exercise, $39.8 \%$ reported exercising one to three times per week, and $32.4 \%$ reported exercising four or more times per week. The mean $( \pm S D)$ age was $69.8 \pm 8.7$ years at baseline. Baseline BMI and waist circumference were $28.7 \pm 5.7 \mathrm{~kg} \cdot \mathrm{m}^{-2}$, and $93.8 \pm 14.6$ $\mathrm{cm}$, respectively. Participants were compliant wearing the accelerometer for $6.6 \pm 0.8$ days.

Table 2 displays the average levels of BMI, WC, and accelerometer-measured variables in different race 
Table 1 Characteristics of Participants $(N=7873)$

\begin{tabular}{|c|c|}
\hline Variable & Total \\
\hline Age, mean (SD), yr & $69.8(8.7)$ \\
\hline Women, n (\%) & $4267(54.2)$ \\
\hline Blacks, n (\%) & $2483(31.5)$ \\
\hline Stroke-belt ${ }^{\mathrm{a}}, \mathrm{n}(\%)$ & $4291(54.5)$ \\
\hline \multicolumn{2}{|l|}{ Education, n (\%) } \\
\hline Less than high school & $493(6.3)$ \\
\hline High school graduate & $1757(22.3)$ \\
\hline Some college & $2119(26.9)$ \\
\hline College graduate and above & $3504(44.5)$ \\
\hline Smoking, n (\%) & $843(10.7)$ \\
\hline Hypertension, n (\%) & $4066(51.6)$ \\
\hline Diabetes, n (\%) & $1256(16.0)$ \\
\hline Body mass index, mean (SD), $\mathbf{k g}^{*} \mathrm{~m}^{-2}$ & $28.7(5.7)$ \\
\hline Waist circumference, mean (SD), cm & $93.8(14.6)$ \\
\hline Systolic blood pressure, mean (SD), $\mathrm{mmHg}$ & $125.3(15.6)$ \\
\hline Diastolic blood pressure, mean (SD), mmHg & $76.1(9.3)$ \\
\hline
\end{tabular}

${ }^{a}$ denotes a region in the United States comprising the states of North Carolina, South Carolina, Georgia, Mississippi, Alabama, Arkansas, Kentucky, Louisiana, and Tennessee

and sex groups. White women had the lowest BMI, WC, STA, and highest LPA, LPA\%, compared to other groups. White men had the highest WC, MVPA and MVPA\% among groups. Black men had similar levels of adiposity as white men, and the most total device wearing time, STA and STA\%. Black women had the highest BMI, and accumulated the least total device wearing time MVPA, MVPA\%, LPA, LPA\%, and the most STA\%.

In the mixed linear regression models, significant interactions existed in BMI by race and sex for the Sqrt
MVPA\%, and WC by race and sex for the Sqrt MVPA\% and the Sqrt LPA\% $(p<0.05)$. Thus, all results were stratified by race and sex for ease of comparability. In subgroup analyses, BMI was inversely associated with Sqrt MVPA\% and Sqrt LPA\%, and positively related to Sqrt STA\% in black women, white men and white women after adjustments for age, region of residence, education, hypertension, smoking, diabetes, time interval between measures. Similar patterns were observed between WC and Sqrt MVPA\%, Sqrt LPA\%, and Sqrt STA\% in all the groups, respectively. BMI was inversely associated with Sqrt LPA\%, and positively related to Sqrt STA\% in black men (Table 3). BMI was not significantly associated with Sqrt MVPA\% in black men $(p=0.792)$.

No interaction was significant for the logistic model of meeting or not meeting the PA guideline, but all results were stratified by race and sex for ease of comparability. A significant relationship also existed between BMI and WC and odds of not meeting the PA guideline in black men, black women, white men, and white women (Table 4). Time spent in vigorous PA was very limited in this cohort (mean \pm SD for vigorous PA: $0.2 \pm 1.7 \mathrm{~min} / \mathrm{d}$ ), indicating those who met the PA guideline were mainly older adults who accumulated $\geq 150 \mathrm{~min}$ of MVPA per week. Participants with higher BMI were less likely to meet the PA guideline (5\% less likely in black men, $9 \%$ in black women, $11 \%$ in white men, and $9 \%$ in white women for those with higher BMI, respectively). The same pattern was found for WC in this study (3\% less likely in black men, $4 \%$ in black women, $4 \%$ in white men, and $3 \%$ in white women for those with higher WC, respectively).

\section{Discussion}

This study employed objective measurements of BMI, WC, PA, and STA in a U.S. national cohort of 7873

Table 2 Adiposity, physical activity, and stationary time by race and sex subgroups (Mean (SD))

\begin{tabular}{|c|c|c|c|c|}
\hline Variable & Black men $(\boldsymbol{n}=933)$ & Black women $(\boldsymbol{n}=1550)$ & White men $(\boldsymbol{n}=2673)$ & White women (2717) \\
\hline Body mass index, $\mathrm{kg} / \mathrm{m}^{2}$ & $28.9(5.1)$ & $31.2(6.6)$ & $28.1(4.6)$ & $27.7(5.8)$ \\
\hline Waist circumference, $\mathrm{cm}$ & $98.5(12.8)$ & $94.3(14.6)$ & $98.9(12.1)$ & $86.9(14.7)$ \\
\hline Total wearing time, $\mathrm{min} /$ day & $899.6(130.1)$ & $884.7(123.7)$ & $896.2(94.9)$ & $885.4(91.3)$ \\
\hline $\operatorname{MVPA}^{a}, \min /$ day & $12.4(17.1)$ & $8.1(12.8)$ & $17.8(20.8)$ & $12.1(16.0)$ \\
\hline $\mathrm{LPA}^{\mathrm{b}}$, min/day & $181.3(83.7)$ & $175.6(80.6)$ & $191.9(76.8)$ & $194.5(75.1)$ \\
\hline $\mathrm{STA}^{\mathrm{c}}$, min/day & $705.9(135.0)$ & $701.0(131.9)$ & $686.5(110.2)$ & $678.8(107.6)$ \\
\hline MVPA\% ${ }^{d}$ & $1.4(1.9)$ & $0.9(1.4)$ & $2.0(2.3)$ & $1.3(1.7)$ \\
\hline LPA $^{e}$ & $20.2(9.0)$ & $20.0(8.9)$ & $21.5(8.3)$ & $22.0(8.3)$ \\
\hline SED $\%^{f}$ & $78.4(9.9)$ & $79.1(9.5)$ & $76.6(9.4)$ & $76.6(9.1)$ \\
\hline
\end{tabular}

${ }^{a}$ MVPA refers to moderate to vigorous physical activity, indicating minutes in which the accelerometer registered $\geq 1065 \mathrm{cpm}$

b LPA refers to light intensity physical activity, indicating minutes in which the accelerometer registered 50-1064 cpm

c STA refers to stationary time, indicating minutes in which the accelerometer registered $<50 \mathrm{cpm}$

${ }^{d}$ Denotes the proportion of total accelerometer wear time spent in moderate to vigorous intensity physical activity

e Denotes the proportion of total accelerometer wear time spent in light intensity physical activity

${ }^{f}$ Denotes the proportion of total accelerometer wear time spent in sedentary behavior 
Table 3 Association ${ }^{\text {a }}$ of adiposity with physical activity and stationary time ( $\left.N=7873\right)$

\begin{tabular}{|c|c|c|c|c|c|c|c|c|c|}
\hline & \multicolumn{3}{|c|}{ Sqrt MVPA\% ${ }^{\mathbf{b}}$} & \multicolumn{3}{|c|}{ Sqrt LPA\% ${ }^{c}$} & \multicolumn{3}{|c|}{ Sqrt STA\% ${ }^{\mathbf{d}}$} \\
\hline & Beta & $P$ & 95\% C.I. & Beta & $P$ & 95\% C.I. & Beta & $P$ & 95\% C.I. \\
\hline \multicolumn{10}{|l|}{ Body mass index } \\
\hline Black men & 0.004 & 0.792 & $-0.023,0.030$ & -0.027 & $<0.001$ & $-0.038,-0.015$ & 0.016 & $<0.001$ & $0.010,0.023$ \\
\hline Black women & -0.017 & $<0.001$ & $-0.021,-0.013$ & -0.029 & $<0.001$ & $-0.036,-0.022$ & 0.016 & $<0.001$ & $0.012,0.020$ \\
\hline White men & -0.036 & $<0.001$ & $-0.041,-0.030$ & -0.028 & $<0.001$ & $-0.035,-0.021$ & 0.020 & $<0.001$ & $0.016,0.024$ \\
\hline White women & -0.022 & $<0.001$ & $-0.026,-0.018$ & -0.021 & $<0.001$ & $-0.027,-0.015$ & 0.015 & $<0.001$ & $0.012,0.018$ \\
\hline \multicolumn{10}{|c|}{ Waist circumference } \\
\hline Black men & -0.009 & $<0.001$ & $-0.012,-0.006$ & -0.012 & $<0.001$ & $-0.017,-0.008$ & 0.008 & $<0.001$ & $0.005,0.010$ \\
\hline Black women & -0.006 & $<0.001$ & $-0.009,-0.003$ & -0.012 & $<0.001$ & $-0.016,-0.007$ & 0.006 & $<0.001$ & $0.004,0.009$ \\
\hline White men & -0.011 & $<0.001$ & $-0.015,-0.008$ & -0.013 & $<0.001$ & $-0.016,-0.010$ & 0.009 & $<0.001$ & $0.007,0.010$ \\
\hline White women & -0.007 & $<0.001$ & $-0.010,-0.005$ & -0.009 & $<0.001$ & $-0.011,-0.006$ & 0.005 & $<0.001$ & $0.004,0.007$ \\
\hline
\end{tabular}

${ }^{a}$ Adjusted by age, region of residence, education, hypertension, smoking, diabetes, and periods of between adiposity and physical activity measures

${ }^{b}$ Denotes the proportion of total accelerometer wear time spent in moderate to vigorous intensity physical activity

c Denotes the proportion of total accelerometer wear time spent in light intensity physical activity

${ }^{d}$ Denotes the proportion of total accelerometer wear time spent in sedentary behavior

older adults enrolled in the REGARDS study. This is one of the first studies to report an association between adiposity and PA and STA in a population of black and white older adults. Lower adiposity was significantly related to higher levels of accelerometer-measured MVPA and LPA and lower levels of STA. Significant interactions were found among BMI/WC by race, sex in nearly all of the regression models. With the magnitude of associations between BMI and PA/SED generally similar across different race and sex subgroups, except with one difference in black men pertaining to Sqrt MVPA\%. Not surprisingly, participants in this study spent most of their accelerometer wear time in STA and LPA, while their time spent undertaking MVPA was extremely limited. A significant relationship also existed between

Table 4 Association ${ }^{\text {a }}$ of adiposity with odds of not meeting the U.S. physical activity guideline ${ }^{\mathrm{b}}(N=7873)$

\begin{tabular}{lccc}
\hline & \multicolumn{2}{l}{ Not meeting the physical activity guideline $\mathbf{b}^{\mathbf{b}}$} \\
\cline { 2 - 4 } & O.R. & $95 \%$ C.I. & $\mathrm{P}$ \\
\hline Body mass index & & $1.01,1.09$ & $<\mathbf{0 . 0 0 1}$ \\
Black men & 1.05 & $1.06,1.13$ & $<\mathbf{0 . 0 0 1}$ \\
Black women & 1.09 & $1.09,1.14$ & $<\mathbf{0 . 0 0 1}$ \\
White men & 1.11 & $1.07,1.12$ & $<\mathbf{0 . 0 0 1}$ \\
White women & 1.09 & & $<\mathbf{0 . 0 0 1}$ \\
Waist circumference & 1.03 & $1.01,1.05$ & $<\mathbf{0 . 0 0 1}$ \\
Black men & 1.04 & $1.02,1.05$ & $<\mathbf{0 . 0 0 1}$ \\
Black women & 1.04 & $1.03,1.05$ & $<\mathbf{0 . 0 0 1}$ \\
White men & 1.03 & $1.03,1.04$ & smoking,
\end{tabular}

${ }^{a}$ Adjusted by age, region of residence, education, hypertension, smoking, diabetes, and periods of between adiposity and physical activity measures ${ }^{b}$ Accumulated $\geq 150$ min a week of moderate-intensity, or 75 min a week of vigorous-intensity aerobic activity, or an equivalent combination adiposity and odds of meeting the PA guideline. Therefore, prevention efforts aimed at promoting weight control may be beneficial to prevent physical inactivity and sedentary lifestyle among older adults.

The relationship between adiposity and PA has been reported in a number of previous cross-sectional studies [30, 31]. Research has consistently identified a negative relationship between adiposity and levels of PA. While most previous studies assessed selfreported PA, some recent studies with objective measures allowed for more reliable estimates of duration and intensity of PA. For example, one study [15] in the NHANES cohort indicated both self-reported and objectively measured MVPA were independently associated with physiological and anthropometric biomarkers, and objectively measured MVPA showed a stronger association with BMI and WC than selfreported MVPA. The British Regional Heart Study [14] using accelerometer measures reported that reduced MVPA and LPA and increased STA were associated with obesity (waist circumference of $>102 \mathrm{~cm}$ ), and low muscle mass in older men. It was also reported that greater time spent in light intensity activity and lower STA were associated with lower BMI in the Lifestyle Interventions and Independence for Elders Study [16]. Additionally, data from the cohort of Health Survey for England [19] indicated total selfreported leisure-time sedentary behaviors and TV time were associated with BMI and $\mathrm{WC}$, while accelerometer-measured sedentary behavior was associated with WC in the cohort of Health Survey for England. Analyses in the NHANES cohort [13, 17] have indicated that adults with high BMI had significantly lower objectively measured MVPA than those with intermediate and ideal BMI. 
A few previous longitudinal studies also demonstrated that obesity/overweight was a significant predictor of PA level later in life. For instance, results from the Iowa Bone Development Study [24] revealed percent body fat measured by dual energy X-ray absorptiometry was associated with subsequent MVPA in childhood. Large cohort studies among adults in U.K. [32] and Australia [33] also showed that obesity at baseline and weight gain led to future physical inactivity and sedentary behaviors. Intriguingly, an analysis from the Medical Research Council Ely Study [34] reported BMI, WC, and fat mass predicted STA, whereas STA did not predict future obesity at 5.6 years of follow-up in U.K. Another study [23] using accelerometers concluded a high baseline body weight and BMI may determine lower levels of MVPA, but STA and PA did not predict weight gain over 6-year follow-up in Norwegian adults.

BMI and WC are both commonly measured as indicators of adiposity. BMI is highly correlated with directly measured fat mass in older adults, while WC provides information on the degree of visceral obesity. In our study, patterns of association of BMI or WC with PA were similar, except for black men. One possible bias of BMI was that it does not distinguish fat mass and fatfree mass. Research has shown that BMI has limited accuracy to estimate body fat percentage, and it is influenced by sex, age and race/ethnicity [35, 36]. Further investigation is needed to better understand the association between adiposity and PA/STA using objective measures like body fat percentage.

The mechanism of adiposity associated with PA is still uncertain. One possible explanation suggested by Godin et al. [37] is that adiposity may impact PA levels by influencing cognition such as intention/motivation and perceived behavioral control, which is based on the Theory of Planned Behavior. Obese or overweight older adults may be less likely to participate in PA because of low self-efficacy, poor body image, less social support, low proficiency in sports, discomfort from heaviness, and low physical functioning [25,38]. Once excess fat is accumulated in earlier life, possibly due to a low level of PA, it may lead to even lower PA participation. The association between adiposity and PA has also been supported by a Mendelian randomization analysis [38] and data from animal models [39]. However, we were not able to examine any further mediating factors, such as self-efficacy, social support, or proficiency in sports, in the association between adiposity and PA. Future studies will be necessary to uncover the mechanism of how adiposity may impact later PA behaviors in older adults.

This study has several strengths. First, the sample was recruited from a well-characterized cohort of midlife and older black and white adults living in the U.S. The participants were also extremely compliant with the 7-day protocol (average wear time per week: $6.6 \pm 0.8 \mathrm{~d}$ ), providing a large pool of quality accelerometer-derived data. Second, we used actual measurements to access the adiposity of participants during an in-home visit, providing more detailed analysis for older white and black women and men. Third, an objective measure of PA was applied to examine relationships between adiposity and objectively measured PA and STA among community-dwelling older adults. This allowed for full analyses of time spent in PA of varying intensity. Finally, this is one of the first studies to examine the relationship between adiposity and meeting the PA guideline in older adults.

The findings of this study were also subject to limitations. First, the cohort was quite sedentary, and there was a significant skewness of the variables of PA and STA. The range of MVPA was extremely narrow, so transformations were performed to ensure normality of distribution. Second, there are limitations to using accelerometers, including not being able to identify types and domains of PA or capture upper-body or nonambulatory movement, potentially resulting in an underestimation of total PA [40]. Accelerometers calibrated and validated on structured activities performed in a laboratory rather than on free-living activities in our study [41] may underestimate MVPA. Accelerometer counts from a hip worn device can be similar for sitting and standing with negligible movement leading to overestimation of time in sedentary behavior and underestimation of LPA. Third, our results were not generalizable for participants who did not wear the accelerometer for a sufficient number of days/hours or did not agree to wear accelerometer. Some of the participant characteristics collected several years prior to being asked to wear accelerometer may have changed. However, with our large sample size, the changes may not significantly impact the group means, proportions, or association. Finally, as a cross-sectional study, causality cannot be inferred. Future research is needed to explicitly address these issues.

\section{Conclusion}

There was a significant association between adiposity and subsequent PA and STA in this cohort with both black and white older adults. A lower degree of adiposity was significantly related to higher levels of MVPA and LPA, and less STA. BMI and WC were also inversely associated with the odds of not accumulating adequate PA to meet the PA guidelines. Race and sex did not influence in the association between adiposity, and PA/SED. The study suggests tailored PA interventions should be developed among overweight and obese older adults.

\section{Abbreviations}

BMI: Body mass index; CPM: Counts per minute; LPA: Light-intensity physical activity; MVPA: Moderate-to-vigorous-intensity physical activity; ORs: Odds 
ratios; PA: Physical activity; REGARDS: REasons for Geographic and Racial Differences in Stroke; STA: Stationary time; WC: Waist circumference

\author{
Acknowledgements \\ The authors thank the other investigators, the staff, and the participants of \\ the REGARDS study for their valuable contributions. A full list of participating \\ REGARDS investigators and institutions can be found at: https://www.uab. \\ edu/soph/regardsstudy/
}

\section{Declarations}

Not applicable.

\section{Authors' contributions}

WZ, SH, and VH conceptualized and designed the study. WZ, ZC, and YS analyzed and interpreted the data. $\mathrm{WZ}, \mathrm{ZC}, \mathrm{VH}, \mathrm{SH}$, and SB contributed in data interpretation and writing the manuscript. All authors read and approved the final manuscript.

\section{Funding}

This research project is supported by a cooperative agreement U01 NS041588 co-funded by the National Institute of Neurological Disorders and Stroke (NINDS) and the National Institute on Aging (NIA), National Institutes of Health, Department of Health and Human Service and investigatorinitiated grant R01NS061846 from the NINDS. Additional funding was supported by the MOE (Ministry of Education in China) Project of Humanities and Social Sciences (20YJC890053), Fundamental Research Funds for the Central Universities (GK201803095) and an unrestricted research grant from the Coca-Cola Company. The funders had no role in the design and conduct of the study; collection, management, analysis, and interpretation of the data; preparation, review, or approval of the manuscript; or the decision to submit the manuscript for publication.

\section{Availability of data and materials}

This study uses data from the Reasons for Geographic and Racial Differences in Stroke (REGARDS) cohort. In order to abide by its obligations with NIH/ NINDS and the Institutional Review Board of the University of Alabama at Birmingham, REGARDS facilitates data sharing through formal data use agreements. Any investigator is welcome to access the REGARDS data through this process. Requests for data access may be sent to regardsadmin@uab.edu.

\section{Ethics approval and consent to participate}

All participants gave verbal consent for telephone interview and accelerometer measures. They also provided written informed consent for inperson physical examination. The study was approved by the institutional review boards of Arizona State University and University of Alabama, Birmingham.

\section{Consent for publication}

Not applicable.

\section{Competing interests}

The authors declare that they have no competing interests.

\section{Author details}

'School of Physical Education, Shaanxi Normal University, No. 620, West Chang'an Avenue, Chang'an District, Xi'an 710119, Shaanxi, China.

2Department of Epidemiology, School of Public Health, University of Alabama at Birmingham, Birmingham, AL, USA. ${ }^{3}$ Department of Biostatistics, School of Public Health, University of Alabama at Birmingham, Birmingham, AL, USA. ${ }^{4}$ Departments of Exercise Science and Epidemiology/Biostatistics, Arnold School of Public Health, University of South Carolina, Columbia, SC, USA. ${ }^{5}$ College of Health and Human Services, San Diego State University, San Diego, CA, USA.
Received: 28 November 2019 Accepted: 22 July 2020

Published online: 28 July 2020

\section{References}

1. Carlson SA, Fulton JE, Pratt M, Yang Z, Adams EK. Inadequate physical activity and health care expenditures in the United States. Prog Cardiovasc Dis. 2015:57:315-23.

2. Carlson SA, Adams EK, Yang Z, Fulton JE. Percentage of deaths associated with inadequate physical activity in the United States. Prev Chronic Dis. 2018;15:1-11.

3. Fishman El, Steeves JA, Zipunnikov V, Koster A, Harris TA, Murphy R Association between objectively measured physical activity and mortality in NHANES. Med Sci Sports Exerc. 2016:48:1303-11.

4. Matthews CE, Keadle SK, Troiano RP, Kahle L, Koster A, Brychta R, et al. Accelerometer-measured dose-response for physical activity, sedentary time, and mortality in US adults. Am J Clin Nutr. 2016;104:1424-32.

5. Piercy LK, Troiano PR, Ballard MR, Carlson AS, Fulton EJ, Galuska AD, et al. The physical activity guidelines for Americans. JAMA. 2018;320:2020-8.

6. Troiano RP, Berrigan D, Dodd KW, Masse LC, Tilert T, Mcdowell M. Physical activity in the United States measured by accelerometer. Med Sci Sports Exerc. 2008;40:181-8.

7. Tucker JM, Welk GJ, Beyler NK. Physical activity in U.S. adults: compliance with the physical activity guidelines for Americans. Am J Prev Med. 2011;40: 454-61.

8. Hooker SP, Hutto B, Zhu W, Blair SN, Colabianchi N, Vena JE, et al. Accelerometer measured sedentary behavior and physical activity in white and black adults: the REGARDS study. J Sci Med Sport. 2016;19:336-41.

9. Aaltonen S, Kujala UM, Kaprio J. Factors behind leisure-time physical activity behavior based on Finnish twin studies: the role of genetic and environmental influences and the role of motives. Biomed Res Int. 2014 2014:931820.

10. Edwards MK, Addoh O, Herod SM, Rhodes RE, Loprinzi PD. A conceptual neurocognitive affect-related model for the promotion of exercise among obese adults. Curr Obes Rep. 2017;6:86-92.

11. Garcia LMT, Diez Roux AV, Martins ACR, Yang Y, Florindo AA. Development of a dynamic framework to explain population patterns of leisure-time physical activity through agent-based modeling. Int J Behav Nutr Phys Act. 2017;14:1-8

12. Elhakeem A, Hannam K, Deere KC, Hartley A, Clark EM, Moss C, et al. Correlates of high-impact physical activity measured objectively in older British adults. J Public Health (Bangkok). 2018:40:727-37.

13. Jones SA, Wen F, Herring AH, Evenson KR. Correlates of US adult physical activity and sedentary behavior patterns. J Sci Med Sport. 2016;19:1020-7.

14. Aggio DA, Sartini C, Papacosta O, Lennon LT, Ash S, Whincup PH, et al. Cross-sectional associations of objectively measured physical activity and sedentary time with sarcopenia and sarcopenic obesity in older men. Prev Med (Baltim). 2016;91:264-72

15. Atienza AA, Moser RP, Perna F, Dodd K, Ballard-Barbash R, Troiano RP, et al. Self-reported and objectively measured activity related to biomarkers using NHANES. Med Sci Sports Exerc. 2011:43:815-21.

16. Bann D, Hire D, Manini T, Cooper R, Botoseneanu A, McDermott MM, et al. Light intensity physical activity and sedentary behavior in relation to body mass index and grip strength in older adults: cross-sectional findings from the lifestyle interventions and independence for elders (LIFE) study. PLoS One. 2015;10:e0116058.

17. Barreira TV, Harrington DM, Katzmarzyk PT. Cardiovascular health metrics and accelerometer-measured physical activity levels: national health and nutrition examination survey, 2003-2006. Mayo Clin Proc. 2014;89:81-6.

18. Biddle SJH, Bengoechea García E, Pedisic Z, Bennie J, Vergeer I, Wiesner G. Screen time, other sedentary Behaviours, and obesity risk in adults: a review of reviews. Curr Obes Rep. 2017:6:134-47.

19. Stamatakis E, Davis M, Stathi A, Hamer M. Associations between multiple indicators of objectively-measured and self-reported sedentary behaviour and cardiometabolic risk in older adults. Prev Med (Baltim). 2012;54:82-7.

20. Myers A, Gibbons C, Finlayson G, Blundell J. Associations among sedentary and active behaviours, body fat and appetite dysregulation: investigating the myth of physical inactivity and obesity. Br J Sports Med. 2017:51:1540-5.

21. Brach JS, VanSwearingen JM, FitzGerald SJ, Storti KL, Kriska AM. The relationship among physical activity, obesity, and physical function in community-dwelling older women. Prev Med (Baltim). 2004;39:74-80. 
22. Di Francesco V, Zamboni M, Zoico E, Bortolani A, Maggi S, Bissoli L, et al. Relationships between leisure-time physical activity, obesity and disability in elderly men. Aging Clin Exp Res. 2005;17:201-6.

23. Ekelund U, Kolle E, Steene-Johannessen J, Dalene KE, Nilsen AKO, Anderssen $S A$, et al. Objectively measured sedentary time and physical activity and associations with body weight gain: does body weight determine a decline in moderate and vigorous intensity physical activity? Int J Obes. 2017;41: 1769-74.

24. Kwon S, Janz KF, Burns TL, Levy SM. Effects of adiposity on physical activity in childhood: lowa bone development study. Med Sci Sports Exerc. 2011;43: 443-8.

25. Riebe D, Blissmer BJ, Greaney ML, Ewing Garber C, Lees FD, Clark PG. The relationship between obesity, physical activity, and physical function in older adults. J Aging Health. 2009;21:1159-78.

26. Howard VJ, Cushman M, Pulley L, Gomez CR, Go RC, Prineas RJ, et al. The reasons for geographic and racial differences in stroke study: objectives and design. Neuroepidemiology. 2005;25:135-43.

27. Garvey WT, Mechanick JI, Brett EM, Garber AJ, Hurley DL, Jastreboff AM, et al. American Association of Clinical Endocrinologists and American College of Endocrinology Comprehensive Clinical Practice Guidelines for Medical Care of Patients With Obesity. Endocr Pract. 2016;22(Supplement 3):1-203.

28. Howard VJ, Rhodes JD, Mosher A, Hutto B, Stewart MS, Colabianchi N, et al. Obtaining accelerometer data in a National Cohort of black and white adults. Med Sci Sports Exerc. 2015;47:1531-7.

29. Hutto B, Howard VJ, Blair SN, Colabianchi N, Vena JE, Rhodes D, et al. Identifying accelerometer nonwear and wear time in older adults. Int J Behav Nutr Phys Act. 2013;10:120.

30. Hansen BH, Holme I, Anderssen SA, Kolle E. Patterns of objectively measured physical activity in Normal weight, overweight, and obese individuals (20-85 years): a cross-sectional study. PLoS One. 2013:8:1-8

31. Júdice PB, Silva AM, Santos DA, Baptista F, Sardinha LB. Associations of breaks in sedentary time with abdominal obesity in Portuguese older adults. Age (Dordr). 2015;37:23.

32. Golubic R, Ekelund U, Wijndaele K, Luben R, Khaw KT, Wareham NJ, et al. Rate of weight gain predicts change in physical activity levels: a longitudinal analysis of the EPIC-Norfolk cohort. Int J Obes. 2013;37:404-9.

33. Pedisic Z, Ding GA, Chau JY, Banks E, Stamatakis E, et al. High sitting time or obesity: which came first? Bidirectional association in a longitudinal study of 31,787 Australian adults. Obesity. 2014;22:2126-30.

34. Ekelund U, Brage S, Besson H, Sharp S, Wareham NJ. Time spent being sedentary and weight gain in healthy adults: reverse or bidirectional causality? Am J Clin Nutr. 2008:88:612-7.

35. Heo M, Faith MS, Pietrobelli A, Heymsfield SB. Percentage of body fat cutoffs by sex, age, and race-ethnicity in the US adult population from NHANES 1999-2004. Am J Clin Nutr. 2012;96:448.

36. Woolcott OO, Bergman RN. Relative fat mass (RFM) as a new estimator of whole-body fat percentage - a cross-sectional study in American adult individuals. Sci Rep. 2018:8:1-11.

37. Godin G, Amireault S, Bélanger-Gravel A, Vohl MC, Pérusse L. Prediction of leisure-time physical activity among obese individuals. Obesity. 2009:17:706-12.

38. Richmond RC, Davey Smith G, Ness AR, den Hoed M, McMahon G, Timpson $\mathrm{NJ}$. Assessing causality in the association between child adiposity and physical activity levels: a Mendelian randomization analysis. PLoS Med. 2014; 11:e1001618.

39. Friend DM, Devarakonda K, Neal TJO, Skirzewski M, Papazoglou I, Kaplan A et al. Basal ganglia dysfunction contributes to physical inactivity in obesity. Cell Metab. 2017;25:312-21.

40. Gorman E, Hanson HM, Yang PH, Khan KM, Liu-Ambrose T, Ashe MC Accelerometry analysis of physical activity and sedentary behavior in older adults: a systematic review and data analysis. Eur Rev Aging Phys Act. 2014; 11:35-49.

41. Hooker SP, Feeney A, Hutto B, Pfeiffer KA, Mclver K, Heil DP, et al. Validation of the actical activity monitor in middle-aged and older adults. J Phys Act Health. 2011:8:372-81.

\section{Publisher's Note}

Springer Nature remains neutral with regard to jurisdictional claims in published maps and institutional affiliations.

Ready to submit your research? Choose BMC and benefit from:

- fast, convenient online submission

- thorough peer review by experienced researchers in your field

- rapid publication on acceptance

- support for research data, including large and complex data types

- gold Open Access which fosters wider collaboration and increased citations

- maximum visibility for your research: over $100 \mathrm{M}$ website views per year

At $\mathrm{BMC}$, research is always in progress.

Learn more biomedcentral.com/submissions 